\title{
A CONSTITUIÇÃO HISTÓRICA DA LEITURA COMO OBJETO DE ENSINO: O DISCURSO OFICIAL E O DIDÁTICO NA DÉCADA DE 1930 NO BRASIL
}

\author{
THE HISTORICAL CONSTITUTION OF READING AS AN OBJECT OF TEACHING: THE \\ OFFICIAL AND DIDACTIC DISCOURSE IN THE 1930S IN BRAZIL
}

\author{
Alanne de Paula Barbosa', Washington Silva de Farias ${ }^{2}$ \\ ${ }^{1}$ Secretaria Municipal de Educação de Casinhas, PE, Brasil \\ alanne_dpb@hotmail.com \\ ${ }^{2}$ Universidade Federal de Campina Grande (UFCG), Campina Grande, PB, Brasil. \\ washfarias@gmail.com
}

Recebido em 30 jul. 2018

Aceito em 28 ago. 2018

Resumo: Este artigo propõe uma reflexão sobre a constituição histórica da leitura como objeto de ensino no discurso de programas e manuais de ensino brasileiros no século XX, especificamente na década de 1930. Buscamos investigar essa constituição no discurso pedagógico do programa oficial de Português instituído pelo governo brasileiro em 1931 e de uma coleção de manuais de ensino de Português do mesmo período. De modo específico, pretendemos: 1) Identificar representações de leitura, de sujeito-leitor e dos modos de ensinar produzidas no discurso do programa e dos manuais selecionados; 2) Verificar em que formações discursivas se inscrevem essas representações; 3 ) Caracterizar os movimentos de interpretação sobre leitura nos dois materiais pedagógicos. A análise do corpus foi realizada de forma comparativa, considerando os efeitos e as relações interdiscursivas entre recortes do programa de ensino e dos manuais didáticos. Nosso estudo se fundamenta na Análise de Discurso de linha francesa e no campo da História das Ideias Linguísticas no Brasil, tendo como referências principais os trabalhos de Orlandi (1998, 2002, 2009), Pêcheux (1990), Razzini (2000) e Souza (1999). As constatações gerais da análise indicam um funcionamento discursivo apoiado em um processo de identificação entre os discursos oficial e didático, com alguns traços de deslocamentos de sentidos, ocasionados por sua recontextualização e reformulação. Este trabalho contribui para a compreensão da constituição histórica da leitura como objeto de ensino e oferece uma visão mais consistente sobre a historicidade pela qual se constituiu esse objeto.

Palavras-chave: Discurso Pedagógico. Programas e Manuais de Ensino. História. Leitura.

\begin{abstract}
This article proposes a reflection on the historical constitution of reading as an object of teaching in the discourse of Brazilian programs and textbooks in the twentieth century, specifically in the 1930s. We seek to investigate this constitution in the pedagogical discourse of the official Portuguese program established by the government Brazilian in 1931 and a collection of Portuguese teaching manuals from the same period. Specifically, we aim to: 1) Identify reading, subject-reader representations and teaching modes produced in the discourse of the program and the selected manuals; 2) Check in which discursive formations these representations are inscribed; 3) To characterize the movements of interpretation on reading in the two pedagogical materials. The analysis of the corpus was performed in a comparative way, considering the effects and the interdiscursive relations between cuts of the teaching program and the textbooks. Our study is based on French Discourse Analysis and on the History of Language Ideas in Brazil, with the main references being Orlandi (1998, 2002, 2009), Pêcheux (1990), Razzini (2000) and Souza (1999). The general findings of the analysis indicate a discursive functioning supported by a process of identification between the official and didactic discourses, with some traces of sense displacements, caused by the recontextualization and reformulation. This work contributes to the understanding of the
\end{abstract}


historical constitution of reading as an object of teaching and offers a more consistent view of the historicity by which this object was constituted.

Keywords: Pedagogical Discourse. Teaching Programs and Manuals. History. Reading.

\section{Introdução}

Este trabalho é parte integrante de uma pesquisa de mestrado ${ }^{1}$, em que é proposta uma reflexão sobre a constituição discursiva da leitura como objeto de ensino em três períodos históricos brasileiros (décadas de 1930, 1940 e 1950). A dissertação fez parte de um projeto mais amplo que investiga o papel que a produção de instrumentos linguísticos e didáticos vem exercendo no Brasil, desde o final do século XIX, na definição do que é ou não nossa língua e como podemos nos constituir como sujeitos dela².

Ao fazer um recorte do objeto de investigação deste projeto maior, delimitamos a leitura como objeto de pesquisa; e, para observar os movimentos de sentidos e gestos de interpretação sobre a leitura e o leitor no Brasil, elegemos para análise o discurso pedagógico de programas e manuais de ensino de Português. Neste artigo, apresentamos reflexões feitas a partir da análise do discurso pedagógico sobre a leitura, o sujeito-leitor e os modos de ensinar produzido na década de 1930.

Buscamos dar respostas aos seguintes questionamentos: como a leitura e o sujeito-leitor se constituíram historicamente no discurso pedagógico do Programa oficial de Português da década de 1930 e dos manuais de ensino de uma coleção didática de Português do mesmo período? Como são representados nesse material os sentidos da leitura, do sujeito-leitor e dos modos de ensinar a leitura? Em que filiações discursivas se inscrevem esses sentidos? O estudo possibilitará entender, portanto, alguns dos movimentos de interpretação que caracterizam o discurso pedagógico oficial e didático no período histórico pesquisado.

O primeiro arquivo de nossa análise é constituído pelo Programa de Ensino de Português formulado pelo Estado para década de 1930. Esse documento oficial

\footnotetext{
${ }^{1}$ A constituição histórica da leitura como objeto de ensino: o discurso oficial e o didático (19301950) (BARBOSA, 2017).

${ }^{2}$ A língua a conhecer, ensinar e aprender no Brasil: o discurso dos instrumentos linguísticos e didáticos (FARIAS, 2012).
} 
propunha uma forma de organização do ensino de Português a partir de conteúdos, exercícios e pela indicação dos próprios modos de ensinar para cada ano escolar. O segundo arquivo é composto por manuais da coleção didática intitulado Programas de Português, do gramático e filólogo Júlio Nogueira (NOGUEIRA, 1938,1939, 1941), produzida também na década de 1930. Os manuais dessa coleção foram organizados por série escolar (1aa $, 2^{\underline{a}}, 3^{\underline{a}}$ e $4^{\underline{a}}$ séries), de modo a atender as exigências do programa oficial. Os espaços escolhidos para extrair os recortes discursivos e observar neles as filiações, representações e movimentos de sentidos sobre a leitura foram os prefácios, a organização da obra e as atividades de leitura.

O período histórico da década de 1930 foi eleito para investigação por demarcar o início da regulamentação do ensino por programas oficiais de abrangência nacional.

Este trabalho é desenvolvido a partir da abordagem discursivo-interpretativa da Análise de Discurso francesa, considerando os efeitos e as relações interdiscursivas entre recortes do Programa de Ensino e dos manuais didáticos selecionados. A análise de programas e manuais de ensino nos permite ter uma visão mais consistente sobre as determinações linguístico-históricas pelas quais se constituem os objetos de ensino de uma matéria escolar, no nosso caso a leitura.

\section{A construção do saber escolar sobre a língua no Brasil}

O conhecimento da língua nacional no Brasil se desenvolveu, inicialmente, a partir de estudos diversos sob a forma de gramáticas, manuais e em outros materiais com finalidades pedagógicas ou, ainda, com fins descritivos. De acordo com Guimarães (2004), os estudos que envolvem nossa língua "vão tomar corpo num movimento geral das ideias que se desenvolve a partir da segunda metade do século XIX" (GUIMARÃES, 2004, p. 23).

Orlandi (2002) desenvolve um trabalho acerca de questões gerais sobre a constituição da língua nacional, do pensamento sobre a linguagem no Brasil e das políticas de língua subjacentes a esse pensamento, e nos esclarece que é preciso pensar que a história das ideias linguísticas e gramaticais tem oscilações. A pesquisadora então nos incita a pensar sobre as alianças existentes entre a história do Brasil e a história da Europa e, assim, os discursos sobre a língua. Essa relação, 
posta pela colonização, nos permite compreender a história de constituição de um saber sobre a língua conexo à construção da própria língua nacional. Deste modo, observamos não a reconstrução de uma história, mas o processo pelo qual ela perpassa.

No contexto brasileiro, esse processo pelo qual a história da língua se desenvolve tem relações complexas com o interdiscurso, com uma história da linguagem em que estão mesclados elementos da cultura europeia e brasileira. Uma distinção teórico-metodológica importante para compreender essas relações interdiscursivas é aquela feita por Orlandi entre língua imaginária e língua fluida:

\begin{abstract}
Em nosso imaginário (a língua imaginária) temos a impressão de uma língua estável, com unidade, regrada, sobre a qual, através do conhecimento de especialistas, podemos aprender, termos controle. Mas na realidade (a língua fluida) não temos controle sobre a língua que falamos, ela não tem a unidade que imaginamos, não é clara e distinta, não tem os limites nos quais nos asseguramos, não sabemos como imaginamos, ela é a profundidade e movimento contínuo. (ORLANDI, 2002, p. 18-19)
\end{abstract}

Ao pontuar essa distinção, a pesquisadora ressalta que essas noções são pensadas uma em relação à outra. Os conceitos de língua imaginária e língua fluida nos ajudam a entender a rede de sentidos na qual estava imersa a leitura na década de 30 do século $\mathrm{XX}$, período de maior sistematização e controle do ensino brasileiro pelo Estado. Através dos documentos oficiais, o Estado propunha, assim, uma forma de controle, imaginário, da língua pelo modo de conceber a leitura enquanto uma prática escolari(zada), definida a partir de parâmetros ligados à tradição retórica.

Nosso modelo de língua nacional reflete a construção de uma língua imaginária regida pela vontade de um Estado forte e tendo como parâmetro sua manifestação literária. Essa língua imaginária foi se consolidando em nosso país sobretudo ao longo dos séculos XIX e XX através da produção intelectual do conhecimento gramatical e linguístico e de sua difusão pelo ensino.

Para melhor situar esse acontecimento, consideramos pertinente retomar 0 trabalho realizado por Razzini (2000). A pesquisadora nos oferece um "breve histórico"3 das transformações pelas quais o ensino de português e literatura passou ao longo dos séculos XIX e XX, tendo como fontes históricas programas de ensino e

\footnotetext{
${ }^{3}$ Trata-se do $2^{\circ}$ capítulo da tese da autora, intitulado "Breve histórico do português e da literatura no ensino secundário: 'a ascensão do português e da literatura brasileira'” (RAZZINI, 2000).
} 
manuais didáticos adotados pelo Colégio Pedro $\|^{4}$. Na parte mencionada da pesquisa de Razzini, encontramos informações importantes sobre a constituição da língua nacional, em especial acerca da década de 1930, que diz respeito ao período de produção e circulação do corpus deste artigo.

Ao observar o contexto escolar brasileiro, Razzini (2000) constata que, no século XIX, a realidade brasileira era bem diferente dos centros europeus. Enquanto aqui a maioria da população permanecia analfabeta, uma pequena elite brasileira se preparava para ingressar no curso secundário, a fim de obter o diploma de bacharel o mais rápido que pudesse. Quanto aos programas de ensino, a autora demonstra que, antes da década de 30 do século XX, as sucessivas mudanças curriculares nos conteúdos de ensino tiveram como referência o Colégio Pedro II, cujos programas eram, em grande parte, adotados em escolas de todo o país. Neste período, a história da língua nacional estava sendo constituída de forma menos controlada pelo discurso oficial do Estado. Só após a Revolução de 1930, a partir da Era Vargas (1930-1945), temos uma regulamentação de âmbito nacional para o currículo da disciplina Português no país.

O primeiro programa de ensino de Português de âmbito nacional foi elaborado nos termos do art. 10, do Decreto no 19.890 de 18 de abril de 1931. Esse decreto regulamentava a organização do ensino secundário no Brasil e deu ensejo à elaboração de programas gerais de ensino para todas as matérias desse nível de ensino. Caber destacar que foi também na década de 1930 que o governo passou a centralizar o "controle dos livros didáticos", transferindo essa incumbência do Colégio Pedro II para o então denominado Ministério da Educação e Saúde (RAZZINI, 2000, p. 101). É no contexto desses processos de oficialização e regulamentação da língua nacional que tratamos, neste artigo, da constituição histórica da leitura como objeto de ensino no discurso do Programa de Português de 1931 e de alguns manuais de ensino do mesmo período.

\section{Uma abordagem histórico-discursiva da linguagem}

\footnotetext{
${ }^{4}$ O Colégio Pedro II é uma tradicional instituição de ensino público federal, localizada no estado do Rio de Janeiro, no Brasil. A instituição, fundada na época do período regencial brasileiro, foi nomeada em homenagem ao imperador do Brasil D. Pedro II. O Colégio integrava um projeto civilizatório mais amplo do império do Brasil e, no plano da educação, pretendia-se a formação de uma elite nacional.
} 
Do ponto de vista da Análise de Discurso francesa, o discurso relaciona sentidos e sujeitos que se constituem ao mesmo tempo no interior de uma formação discursiva (FD) e se confrontam entre outras diferentes formações, que são "um princípio de organização para o analista e são parte da constituição dos discursos e dos sujeitos." (ORLANDI, 1998, p. 13).

No contexto da produção didática nacional, essas formações se fazem representar nos gestos de interpretação do governo (discurso oficial) pela forte presença de marcas europeias e ainda por suas relações com o Estado e a Ciência. Assim sendo, tomamos como objeto de análise neste artigo os discursos pedagógicos oficial e didático brasileiros sobre a leitura da década de 1930. As materialidades que serão analisadas correspondem ao discurso do programa oficial para o ensino língua portuguesa de $1931^{5}$, que funciona como discurso pedagógico regulador; e à coleção didática Programa de Português, de Júlio Nogueira, que atua como discurso didático.

A produção de sentidos nesses materiais é tomada como um processo simbólico de produção de interpretações do real histórico e do próprio sujeito, determinado por condições históricas e ideológicas específicas, processo simbólico que dá margem para os gestos de interpretação, formulação e recontextualização de sentidos para a leitura, o sujeito-leitor e os modos de ensinar.

A formulação, como acontecimento discursivo, é uma atualização da memória discursiva, que se faz materialmente pela colocação do discurso em texto, dando corpo aos sentidos. Ao tratar sobre a formulação na análise do corpus, buscamos compreender como os discursos - oficial e didático - significam a partir de sua filiação a uma rede de memória, responsável por fazer os dizeres retornarem, dando ensejo a retomadas e também deslocamentos, redefinições e recontextualizações de sentidos. Segundo Courtine (2014), a memória é a possibilidade de articulação do processo discursivo, permitindo caracterizar essas repetições, rupturas, transformações ou mesmo os esquecimentos que a formam.

Interdiscursivamente, os gestos de interpretação do programa e dos manuais de Português aqui observados revelam essas implicações através dos efeitos de

\footnotetext{
${ }^{5}$ Embora tenha sido formulado para o ano de 1931, esse programa vigorou durante toda a década, sendo modificado apenas em 1942.
} 
sentidos produzidos para a leitura, contribuindo na compreensão da constituição histórica e heterogênea deste objeto de ensino.

\section{Metodologia}

Este trabalho está filiado ao campo teórico da Análise de Discurso, sendo de natureza qualitativa, adotando a abordagem discursiva pecheutiana, que considera a leitura-análise dos discursos como um batimento entre descrição e interpretação (PÊCHEUX, 1990). O corpus do trabalho é do tipo arquivo, que, segundo Courtine (2014), é aquele constituído de materiais textuais pré-existentes, organizados em um conjunto de sequências orais ou escritas segundo um plano definido pelo analista e em função das questões e das condições de produção específicas do discurso analisado. No caso presente, nosso corpus é composto de sequências de dois textos distintos em sua materialidade, mas que estão constitutivamente (e discursivamente) relacionados: o Programa oficial do Estado para o ensino de Português de 1931 e manuais de ensino da coleção Programa de Português, de Júlio Nogueira, produzidos na década de 1930.

Para análise do Programa de Ensino, elegemos como recortes discursivos as passagens referentes aos conteúdos sobre leitura. Já nos manuais didáticos, selecionamos recortes dos prefácios, organização dos conteúdos e das atividades de leitura propostas. Os prefácios, por conterem informações preliminares sobre o que pretendem as obras e sinalizarem os gestos de interpretação do autor; a organização da obra, por corresponder à seleção e disposição dos conteúdos para ensinar e praticar a leitura; e as atividades de leitura, por indicarem as práticas didáticas de leitura legitimadas pelos manuais.

A análise do corpus foi realizada de forma comparativa, considerando as relações interdiscursivas entre recortes do texto do Programa e dos manuais.

\section{A leitura no discurso oficial e didático na década de 1930: Programa $x$ manuais}


Efetuada a análise do corpus selecionado, verificamos um funcionamento do discurso sobre a leitura apoiado num processo de identificação entre o discurso pedagógico dos manuais e o discurso oficial do programa.

Esse processo se caracteriza pela retomada, no discurso dos manuais, das representações (efeitos de sentido) textualizadas no programa oficial sobre a leitura, o sujeito-leitor e os modos de ensinar a leitura. Essa retomada de sentidos produz um efeito de identificação estreita entre os dois discursos. No entanto, constatamos também que, na relação entre esses discursos, há movimentos de deslocamento de sentidos, produzindo efeitos nem sempre coincidentes entre um e outro.

De modo geral, a leitura, em ambos os discursos, é representada a partir de uma perspectiva literária vinculada à tradição retórico-poética, que tem como elementos característicos o desenvolvimento das habilidades do "bem" falar, escrever e admirar as composições escritas (SOUZA, 1999). Em consequência desta representação de leitura, a imagem de sujeito-leitor depreendida desses discursos se caracteriza como aquele que deve ser capaz de exprimir-se corretamente, nas formas orais e escritas. Quanto aos modos de ensinar a leitura, depreende-se dos dois discursos que estes se relacionam a estratégias de oralizar os textos e estudar o vocabulário, em geral centradas na figura do professor, sendo este responsável pela mediação do ensino.

Feitas essas constatações gerais sobre o funcionamento dos discursos sob análise, passamos à consideração dos recortes discursivos que as justificam.

\subsection{O discurso do Programa de Português de 1931}

O Programa de Ensino de Português trazia a indicação sucinta das horas de ensino para cada série, dos conteúdos e dos métodos para ensiná-los; sistematizava as indicações para as séries de $1^{\text {a }}$ a $5^{\text {a }}$, recomendando 4 horas para as primeiras e segundas séries, 3 horas para a terceira, 3 horas para a quarta e 3 horas para 0 quinta série escolar.

De acordo com o documento, o ensino de língua, em geral, deveria ser realizado mediante atividades de leitura, composição oral (recitação), composição escrita e, por último, pelo estudo gramatical, este "baseado no livro de leitura". Por essa disposição, observamos que o Programa de ensino cria um vínculo entre leitura 
e gramática: ao subordinar o lugar do estudo gramatical à leitura, esta é apresentada como conteúdo fundamental e primeiro a ser abordado no ensino de língua.

Os recortes $\mathrm{RP} 0^{6} 1,2$ e 3, abaixo, correspondem às indicações do Programa de ensino de Português de 1931 sobre a leitura para as quatro séries de ensino:

RP30 1:

Leitura de trechos de prosadores e poetas contemporâneos, escolhidos de acôrdo com a capacidade média da classe. Explicação dos textos. Estudo metódico do vocabulário. Reprodução oral do assunto lido. (Português - Primeira e Segunda séries).

RP30 2:

Leitura de excertos de prosadores e poetas modernos. Explicações dos textos. Estudo metódico do vocabulário. Composição oral. (Português - Terceira série).

RP30 3:

Leitura e interpretação de trechos de poetas e prosadores dos dois últimos séculos. Análise literária elementar. (Português - Quarta série).

Nos recortes RP30 1, 2 e 3, a representação literária da leitura é indicada pela reiterada menção a sua prática a partir de trechos/excertos de "prosadores e poetas". As indicações do Programa inscrevem a leitura à filiação retórico-poética, que, conforme já mencionamos, remete a habilidades e saberes ligados à apreciação da escrita literária, considerada como modelo e norma de expressão e beleza.

As indicações do documento pedagógico oficial encerram um gesto de interpretação próprio, que é o de apresentar os autores através do critério pedagógico de apresentação cronológica inversa dos textos, dos mais recentes para os mais antigos. Esse procedimento metodológico se justifica, provavelmente, pelo objetivo de facilitar a recepção dos textos pelos aprendizes, começando pela abordagem daqueles mais familiares e próximos do contexto cultural do aluno, ficando os menos recentes para as séries mais avançadas. As recomendações de ensino de leitura através de textos mais curtos - "trechos/excertos" - também podem ser justificadas por motivação de ordem pedagógica: facilitar a assimilação durante atividade de leitura.

${ }^{6}$ RP30 - Recorte do Programa da década de 1930. 
O ensino de leitura em todas as séries do Programa segue uma ordem específica: primeiro a leitura, seguida de explicação e estudo do vocabulário e, depois, exercícios de reprodução oral, composição oral e análise literária.

As referências a "Explicação dos textos", "Estudo metódico do vocabulário", "Reprodução oral do assunto lido", "Composição oral" e "Análise literária elementar" realçam os modos de ensinar a leitura dominantes na época. Esses modos indiciam que o ensino de leitura estava atrelado à presença fundamental da explicação do professor - sujeito autorizado para realizar a leitura e que deveria orientar os alunos na interpretação dos textos lidos em sala.

Na recomendação "Estudo metódico do vocabulário", a leitura é compreendida como apreensão do vocabulário da língua, pela qual o aluno teria de "captar" os sentidos das palavras e reproduzi-los, ordenadamente.

$\mathrm{Na}$ análise contrastiva entre os RP30 1 e 2 e o RP30 3, notamos um deslizamento quanto à denominação da atividade de leitura, referida como explicação, interpretação e análise. Essa variedade de denominações sugere um possível deslocamento da imagem atribuída à leitura: de uma leitura passiva, recebida do professor (leitura-explicação), para uma leitura com possível participação do aluno (leitura-interpretação e leitura-análise). A prática de leituraanálise, literária, fica restrita à série mais avançada do curso secundário (a quarta), reforçando a ideia de que, nessa série, o aluno estaria apto a assimilar, com maior proveito, os exemplos da linguagem de prestígio da época.

A representação dominante do sujeito-leitor, no Programa, é caracterizada pela repetição formal. De acordo com Orlandi (1998, p. 208), essa repetição se traduz na "técnica de produzir frases" que não historicizam os sentidos e "não fazem trabalhar a ligação do sujeito com a memória discursiva." No entanto, há algum espaço, no Programa, para a representação do sujeito-leitor intérprete, indiciada no programa da $4^{a}$ série, quando menciona conteúdos a serem trabalhados mediante "análise literária elementar".

Os modos de ensinar, por sua vez, se representam, predominantemente, pelas estratégias de explicação do texto, estudo do vocabulário e atividades de reprodução, ancorados na figura do professor. 
Considerando as relações interdiscursivas entre o discurso do Programa oficial de 1931 e o discurso dos manuais de ensino produzidos na mesma década, passamos à análise da coleção Programa de Português, de Júlio Nogueira.

\subsection{A coleção Programa de Português, de Júlio Nogueira}

Cabe chamar a atenção para o fato de que analisamos o discurso sobre o mesmo objeto (a leitura) em materialidades diferentes (programa de ensino e manual didático), o que pode produzir deslocamentos de uma a outra posição e produzir diferentes efeitos de sentido para a leitura.

A primeira versão do conjunto didático Programa de Português foi produzida na década de $1930^{7}$. Júlio Nogueira, seu autor, foi um professor, filólogo e autor de manuais didáticos que viveu na primeira metade do século $X X$, período em que atuou e se destacou como produtor de conhecimento sobre a língua nacional.

A coleção Programa de Português é composta de manuais didáticos destinados às séries de $1^{\text {a }}$ à $4^{\text {a }}$ do ensino fundamental, e foi publicada pela Companhia Editora Nacional, fazendo parte da $2^{\underline{a}}$ Série da coleção de livros didáticos da Biblioteca Pedagógica Brasileira da Companhia Editora Nacional. A coleção foi elaborada para auxiliar o ensino de língua portuguesa e está dividida em 03 volumes: um livro para $1^{\underline{a}}$ e $2^{\underline{a}}$ séries; um para $3^{\underline{a}}$ série e o outro destinado à $4^{\underline{a}}$ série.

O vínculo estreito desses manuais com o Programa de ensino de Português de 1931 pode ser ressaltado, de início, por dois elementos: a divisão dos manuais por níveis escolares, que reproduz a organização por séries do Programa; e a própria denominação dos manuais como "Programa" de Português, que faz referência à designação do documento oficial: "Programa" de Ensino.

Para analisar o funcionamento geral, bem como as representações da leitura, do sujeito-leitor e dos modos de ensinar no discurso da coleção didática Programa de Português, fizemos a seleção do manual das $1^{\underline{a}}$ e $2^{\text {a }}$ séries, do qual consideramos recortes de seus prefácios, da organização estrutural e das atividades de leitura. Elegemos apenas um manual dentre os três da coleção por representar

\footnotetext{
${ }^{7}$ Essa coleção circulou também nas décadas de 1940 e 1950, com reformulações exigidas pelos programas de ensino dessas décadas. 
com bastante regularidade as características dos demais volumes. No entanto, a fim de reiterar certos efeitos de sentido textualizados no manual selecionado, ou para indicar sentidos outros do discurso da coleção Programa de Português, utilizamos, complementarmente, recortes dos outros manuais da coleção.

O manual destinado às $1^{\text {a }}$ e $2^{\underline{a}}$ séries (NOGUEIRA, 1938) está composto do "Índice alfabético das lições"; "Lista alfabética dos autores estudados"; dois textos introdutórios, intitulados "A orientação dêste livro" e "Método para todas as lições"; reprodução do texto do programa oficial de português para as duas séries em questão; lições gramaticais (e seus exercícios de "recapitulação"); trechos de textos literários acompanhados de pequena biografia dos seus autores, seguidos de textos explicativos para cada fragmento literário.

A seleção de textos adotada no manual está de acordo com a indicação oficial para o estudo de trechos literários contemporâneos (para 1ํㅡㄹ e $2^{a}$ séries). No manual, os textos utilizados tratam de assuntos diversos, remetendo às ideias de nacionalismo, exaltação da língua e das regiões brasileiras. Pela seleção de textos e temáticas, observamos um controle da leitura pela proposição e imposição de um arquivo delimitado pelos temas nacionalistas e regionais, abordados segundo a perspectiva literária.

Considerando os textos introdutórios do manual, verificamos que o primeiro traz uma apresentação do livro, com informações sobre a indicação das séries e uma explicação sobre a função do professor no ensino; o segundo apresenta orientações ao docente sobre como proceder ao ensino de língua. Nesse segundo texto, conforme recorte RM30 1, abaixo, encontramos elementos que definem, inicialmente, o gesto de interpretação do manual sobre a leitura, o leitor e modos de ensinar:

$\mathrm{RM} 30^{8}$ 1:

Êste livro apresenta, depois de cada lição, trechos cuidadosamente escolhidos de escritores que honraram as nossas letras. Tais trechos de proporções sempre reduzidas, devem ser lidos, em primeiro lugar, pelo professor. Em seguida, êste verificará se a classe entendeu a leitura, para o que poderá determinar que alguns alunos façam um resumo do que ouviram. Depois, a leitura será feita pelos alunos que mais precisarem dêste exercício. Ministrará o docente a significação de algum termo desconhecido. (Prefácio do Manual de $1^{\mathrm{a}}$ e $2^{\mathrm{a}}$ séries - grifos nossos).

$\overline{{ }^{8} \mathrm{RM} 30}$ - Recorte do Manual da década de 1930. 
No RM30 1, a representação da leitura literária pode ser observada pela menção à escolha de trechos de "escritores que honraram as nossas letras". Pela recomendação de ensinar a leitura a partir dos "trechos de proporções sempre reduzidas", podemos perceber a interdiscursividade com o do Programa oficial, que sugere a abordagem didática da leitura através de textos curtos (excertos/trechos). No texto do manual, a opção pela leitura de trechos é enfatizada pelo uso do advérbio "sempre", sugerindo se tratar de uma orientação didática acatada de forma inconteste.

No recorte sob análise, podemos apreender também sentidos e representações dos modos de ensinar a leitura que não estão tão explicitados no discurso do Programa, embora já indiciados em sua textualidade. Assim, podemos constatar um modo de ensinar centrado na figura do professor, já que a ele cabe a tarefa de realizar a leitura ("em primeiro lugar, pelo professor"); verificar a compreensão dos alunos ("verificação do entendimento da leitura"); ministrar o estudo do vocabulário ("ministra a significação de algum termo desconhecido"). Outra constatação que pode ser feita a partir do recorte é que a leitura tem como finalidade a produção de "resumo": portanto, ao leitor caberia a atividade de reproduzir a leitura que foi lida/explicada pelo professor, o que remete à imagem de um leitor reprodutor.

Verificamos ainda, em relação ao manual sob análise, uma apreensão da leitura como pretexto para o trabalho com a gramática, pois os trechos literários servem às lições gramaticais, que, de modo geral, tratam sobre vocabulário, etimologia e classes de palavras. Este gesto de interpretação do manual sobre a leitura desloca o sentido do gesto do Estado sobre o programa de ensino: enquanto neste há uma ênfase sobre a leitura de textos, na prática do manual, a leitura é pretexto para o estudo da gramática.

No manual de 4⿳亠丷a série, o trabalho com a leitura e interpretação de textos reitera a representação de leitor reprodutor, conforme se pode observar em RM30 2:

RM30 2:

Lido o trecho e mais ou menos compreendido por todos, cumpre interpretá-lo, isto é, indicar o seu sentido, repetir, por outras palavras, o que disse o autor. (Texto instrutivo para o ensino de interpretação do Manual de 4⿳亠丷a série - grifos nossos). 
A imagem de sujeito-leitor como reprodutor formal dos sentidos está referida, neste recorte, pelo gesto do autor sobre o que seja a "interpretação": a indicação do sentido do texto através de outras palavras. Ao leitor, cabe, portanto, a função de repetir, com outras palavras, o que "quis dizer" o autor. Essa representação é reiterada no discurso do manual de $4^{\text {a }}$ série, conforme se pode observar no RM30 3 , onde divisamos uma imagem de leitor orador:

RM30 3:

A leitura em voz alta, nas classes, traz, todavia, excelentes resultados. Algumas crianças aprendem a ler contentando-se com repetir o que está no papel, mas de maneira entrecortada, sem expressão, sem vida. [...] Alguns oradores prejudicam o efeito de trechos excelentes porque lêem mal. (Texto instrutivo para o ensino de leitura do Manual de $4^{\mathrm{a}}$ série - grifos nossos).

No RM30 3, pela representação de leitura como expressão oral efetivada pela "leitura em voz alta" e pela menção a "alguns oradores", podemos depreender a imagem de leitor como "orador". No recorte, são elencadas características indesejadas do leitor-orador, que "prejudicam" a leitura "correta". Assim, há dois perfis de aluno-leitor mobilizados no recorte RM30 3: de um lado, o que "lê mal", aquele que lê de maneira "entrecortada", "sem expressão", "sem vida"; e, do outro, o ideal, aquele que deve ler, pela "repetição do que está no papel", com fluência, vitalidade. Nesse sentido, reitera-se a imagem de sujeitos reprodutores filiados à tradição retórica, caracterizados pelas qualidades sugeridas, por denegação, no trecho: expressividade, vivacidade.

Segundo Souza (1999, p. 93), o mais vasto de todos os efeitos da formação retórica definiu-se como o próprio caráter nacional: "os brasileiros seriam semelhantes à representação platônica dos atenienses, isto é, inveterados "faladores"”. Deste modo, a impregnação da retórica influenciou os objetivos e as práticas de ensino no país, visto que se buscava a formação de alunos "faladores" (oradores). Embora essa influência não tenha sido tão assídua no século $\mathrm{XX}$ como foi na educação retórica do século XIX, os seus objetivos permaneceram no discurso pedagógico brasileiro da década de 1930, conforme destaca a análise do manual de Júlio Nogueira.

\section{Considerações Finais}


Neste trabalho, buscamos investigar a constituição histórica da leitura e do sujeito-leitor no discurso pedagógico do Programa oficial de ensino de Português e de uma coleção de manuais de ensino da década de 1930. Em função de nossas questões e objetivos, verificamos um funcionamento discursivo geral apoiado num processo de identificação entre o discurso oficial dos programas e o discurso pedagógico dos manuais quanto aos sentidos atribuídos à leitura. Contudo, constatamos também haver movimentos de deslocamento de sentidos entre os discursos confrontados, através do processo de recontextualização, resultando em efeitos nem sempre coincidentes entre um e outro discurso.

A filiação da leitura à tradição retórico-poética é comum nos discursos analisados. Essa filiação diz respeito, essencialmente, ao desenvolvimento de três habilidades distintas: a apreciação de obras literárias alheias; a "arte" de escrever, pelo aperfeiçoamento da expressão escrita, através da utilização de instrumentos e artifícios empregados pelos autores estudados; e a oralidade como prática oral expressiva.

No discurso pedagógico do Programa de 1931, a representação de leitura literária está intimamente relacionada à filiação retórica. Essa imagem de leitura reconhece, nos textos literários, modelos e exemplos ilustrativos com os quais os alunos devem ter contato para depois compor seus próprios textos. As representações de sujeito-leitor são de reprodutor e orador, sugeridas e observadas nas recomendações às atividades de oralização de textos e estudo do vocabulário.

No discurso dos manuais de 1930, foi observada uma identificação com o discurso do Programa, reiterando os efeitos de sentidos de leitura literária, pelo atendimento à indicação de apresentar e trabalhar com textos de cunho literário. $\mathrm{A}$ retomada da representação de sujeito-leitor reprodutor se caracteriza pela reprodução formal dos sentidos indicados pelo discurso do autor do manual e das exigências de leitura oral perfeita. Os modos de ensinar, em geral, indicam uma prática de leitura centrada na figura do professor, e retomam as estratégias de ensino textualizadas no discurso oficial do programa, que recomendam o estudo da leitura atrelado à "explicação de textos", ao estudo metódico de vocabulário e às práticas de oralização de textos.

Essas constatações contribuem para a compreensão dos saberes e filiações que, ao longo da história, constituem e legitimam os objetos de ensino de uma 
disciplina. Pela análise efetuada, pudemos verificar ainda que alguns dos modos de pensar e ensinar a leitura legitimados no discurso pedagógico contemporâneo têm sua origem nas práticas históricas com e desse objeto. Exemplo disso são o exercício mecânico de práticas de oralidade, a leitura pensada como pretexto para ensino da gramática e o ensino centrado na figura do professor.

\section{REFERÊNCIAS}

BARBOSA, A. D. P. A constituição histórica da leitura como objeto de ensino: o discurso oficial e o didático (1930-1950). 2017. 134 f. Dissertação (Mestrado em Letras) - Universidade Federal de Campina Grande, Campina Grande, 2017.

COURTINE, J-J. Análise do discurso político: o discurso comunista dirigido aos cristãos. São Carlos: EduFScar, 2014.

FARIAS, W. S. A língua a conhecer, ensinar e aprender no Brasil: o discurso dos instrumentos linguísticos e didáticos. Projeto e plano de trabalho apresentado ao Programa de Pós-Graduação em Linguagem e Ensino do CH/UFCG, 2012.

GUIMARÃES, E. História da Semântica: sujeito, sentido e gramática no Brasil. Campinas, SP: Pontes, 2004.

NOGUEIRA, J. Programa de Português de $1^{\underline{a}}$ e $2^{\underline{a}}$ séries secundárias, volume 82. São Paulo: Companhia Editora Nacional, 1938.

Programa de Português da $3^{\mathrm{a}}$ série secundária, volume 91 . São Paulo: Companhia Editora Nacional, 1939.

. Programa de Português da $4^{a}$ série secundária, volume 105. São Paulo: Companhia Editora Nacional, 1941.

ORLANDI, E. (Org.). A leitura e os leitores. Campinas, SP: Pontes, 1998.

Língua e conhecimento linguístico: para uma história das ideias no Brasil. São Paulo: Cortez, 2002, p. 9-32.

Língua brasileira e outras histórias: discurso sobre a língua e ensino no Brasil. Campinas, SP: RG, 2009, p. 11-19; 171-193. 
Programa de Ensino para o Curso Secundário. Edição da Livraria do Globo: Barcellos, Bertaso \& Cia, Porto Alegre, 1938.

PÊCHEUX, M. Discurso: estrutura ou acontecimento. Trad. Eni Orlandi. Campinas, SP: Pontes, 1990.

RAZZINI, M. P. G. O espelho da nação: a Antologia Nacional e o ensino de português e de literatura (1838-1971). Tese de Doutorado - Instituto de Estudos da Linguagem, UNICAMP, São Paulo, 2000.

SOUZA, R. A. de. 0 império da eloquência: retórica e poética no Brasil oitocentista. Rio de Janeiro: EdUERJ: EdUFF, 1999.

VECHIA, A.; LORENZ, K. M. (Orgs.) Programa de ensino da escola secundária brasileira: 1850-1951. Curitiba: Editora do Autor, 1998.

\section{Sobre os autores}

\section{Alanne de Paula Barbosa}

Mestre pelo Programa de Pós-Graduação em Linguagem e Ensino, da Universidade Federal de Campina Grande (UFCG). Especialista em Ensino de Língua Portuguesa para a Educação Básica nesta mesma Universidade. Graduada no Curso de Letras - Licenciatura Plena em Língua Portuguesa, pela Universidade Estadual da Paraíba (UEPB). Atualmente, exerce a função de Educadora de Língua Portuguesa no Colégio Marista Pio XII e atua como Coordenadora Interna na Secretaria Municipal de Casinhas - Pernambuco.

\section{Washington Silva de Farias}

Possui Doutorado em Linguística pela Universidade Federal da Paraíba (2010), Mestrado em Linguística pela Universidade Federal do Ceará (1998) e Licenciatura em Letras pela Universidade Federal da Paraíba (1991). Professor efetivo da Universidade Federal de Campina Grande. Tem experiência na área de Linguística, com ênfase em Análise do Discurso, atuando principalmente nos seguintes temas: constituição e representação discursiva de sujeitos e sentidos; discurso, memória e identidades; discurso, educação e ensino. 